\title{
Prostate cancer cell phenotypes based on AGR2 and CD10 expression
}

Melissa E Ho ${ }^{1,2}$, Sue-Ing Quek ${ }^{1,2}$, Lawrence D True ${ }^{3}$, Colm Morrissey ${ }^{1}$, Eva Corey ${ }^{1}$, Robert L Vessella ${ }^{1,4}$, Ruth Dumpit ${ }^{5}$, Peter S Nelson ${ }^{5}$, Erin L Maresh ${ }^{6}$, Vei Mah ${ }^{6}$, Mohammed Alavi ${ }^{6}$, Sara R Kim ${ }^{6}$, Lora Bagryanova ${ }^{6}$, Steve Horvath ${ }^{7}$, David Chia ${ }^{6,8}$, Lee Goodglick ${ }^{6,8}$ and Alvin Y Liu ${ }^{1,2}$

${ }^{1}$ Department of Urology, University of Washington, Seattle, WA, USA; ${ }^{2}$ Institute for Stem Cell and Regenerative Medicine, University of Washington, Seattle, WA, USA; ${ }^{3}$ Department of Pathology, University of Washington, Seattle, WA, USA; ${ }^{4}$ Puget Sound VA Medical Center, Seattle, WA, USA; ${ }^{5}$ Division of Human Biology, Fred Hutchinson Cancer Research Center, Seattle, WA, USA; ${ }^{6}$ Department of Pathology and Laboratory Medicine, David Geffen School of Medicine, University of California, Los Angeles, CA, USA; ${ }^{7}$ Department of Biostatistics, David Geffen School of Medicine, University of California, Los Angeles, CA, USA and ${ }^{8}$ Jonsson Comprehensive Cancer Center, David Geffen School of Medicine, University of California, Los Angeles, CA, USA

The combination of expression patterns of AGR2 (anterior gradient 2) and CD10 by prostate cancer provided four phenotypes that correlated with clinical outcome. Based on immunophenotyping, CD10 low AGR2 ${ }^{\text {high }}, \mathrm{CD}_{10}{ }^{\text {high }} \mathrm{AGR2}{ }^{\text {high }}, \mathrm{CD} 0^{\text {low }} \mathrm{AGR2}{ }^{\text {low }}$, and CD10 ${ }^{\text {high }} \mathrm{AGR2}{ }^{\text {low }}$ were distinguished. AGR2 ${ }^{+}$tumors were associated with longer recurrence-free survival and $\mathrm{CD}_{10}{ }^{+}$tumors with shorter recurrence-free survival. In high-stage cases, the CD10 ${ }^{\text {low }}$ AGR2 ${ }^{\text {high }}$ phenotype was associated with a ninefold higher recurrencefree survival than the CD10 ${ }^{\text {high }} A G R 2^{\text {low }}$ phenotype. The CD10 ${ }^{\text {high }}$ AGR2 $2^{\text {high }}$ and CD10 low AGR2 ${ }^{\text {low }}$ phenotypes were intermediate. The $\mathrm{CD}_{10}{ }^{\text {high }} \mathrm{AGR} 2^{\text {low }}$ phenotype was most frequent in high-grade primary tumors. Conversely, bone and other soft tissue metastases, and derivative xenografts, expressed more AGR2 and less CD10. AGR2 protein was readily detected in tumor metastases. The CD10 ${ }^{\text {high }}$ AGR2 ${ }^{\text {low }}$ phenotype in primary tumors is predictive of poor outcome; however, the CD10 ${ }^{\text {low } A G R 2}{ }^{\text {high }}$ phenotype is more common in metastases. It appears that AGR2 has a protective function in primary tumors but may have a role in the distal spread of tumor cells.

Modern Pathology (2013) 26, 849-859; doi:10.1038/modpathol.2012.238; published online 25 January 2013

Keywords: AGR2; bone and soft tissue metastases; cancer cell phenotypes; CD10; patient stratification; prostate cancer; xenografts

Although prostate cancer is the most frequent cancer in men, only a minority of affected men die of the disease. Serum levels of prostate-specific antigen (PSA/KLK3) are widely used to screen men for prostate cancer. However, with a false-positive rate of nearly $70 \%$ many unnecessary biopsies are being performed. ${ }^{1}$ Prostate cancer is histologically characterized by the Gleason grading system. Cases with predominantly pattern 3 tumor predict longterm survival, with or without active intervention.

Correspondence: Dr AY Liu, PhD, Department of Urology, University of Washington, Box 358056, 850 Republican Street, Seattle, WA 98195-6100, USA.

E-mail: aliu@uw.edu

Received 20 September 2012; revised 12 October 2012; accepted 13 October 2012; published online 25 January 2013
Cases with a pattern 4 or pattern 5 component are associated with poorer outcomes. For many patients, PSA level and Gleason score, in addition to post-surgery clinical staging, show relatively good performance in disease prognosis (the Partin nomogram-http://urology.jhu.edu/prostate/ partintables.php). ${ }^{2}$ There remain many cases where the known predictors fail. Thus, not only are informative biomarkers needed to detect early stage cancer with good confidence but also, more importantly, to identify patients whose cancer requires treatment. An early and reliable differentiation between patients with good vs poor prognosis cancer could substantially reduce unnecessary morbidity-generating interventions for long-term survivors. Molecular signatures that provide objective classification will eventually enable such 
categorization of patients. In addition, such a categorization would ideally be made using either small biopsies or biofluids such as urine or blood.

Prostate cancer cells differentially express AGR2 (anterior gradient 2) and CD10/MME (membrane metalloendopeptidase). AGR2 encodes a 19-kDa secreted protein, and $M M E$ encodes a $100-\mathrm{kDa}$ cell surface membrane protein. AGR2 expression is increased in prostate cancer cells (and cells of high-grade prostatic intraepithelial neoplasia, PIN) compared with the normal counterpart luminal epithelial cells. ${ }^{3-6}$ CD10, in contrast, is decreased in cancer cells, although about $30 \%$ of tumors express CD10. ${ }^{7-9}$ Tumors with CD10 ${ }^{+}$cancer cells tend to be more frequent in higher Gleason score cancers, and $\mathrm{CD}^{+}{ }^{+}$cancer cells predominate in regional lymph node metastases. ${ }^{8-10}$ Conversely, AGR2 ${ }^{+}$tumors predominate in lower Gleason score cancers, and cancer cells of Gleason patterns 4 and 5 tend to express lower levels of AGR2.5,6

Expression of CD10 by prostate cancer correlates with poor disease outcome and lower rates of patient survival. ${ }^{9-11}$ In addition, cytoplasmic rather than membraneous localization of the CD10 protein in tumor cells is associated with poor outcome. ${ }^{11}$ This finding could be attributed to the association of CD10 with cytoplasmic heat-shock proteins such HSP27 (HSPB1) in prostate cancer cells; CD10 ${ }^{+}$ luminal cells do not express HSP27. ${ }^{12}$ In contrast, prostate cancer expression of AGR2 correlates with longer patient survival. ${ }^{5}$ Could differential expression by cancer cells of CD10 and AGR2 provide more precise prognostic information?

In this study, expression of AGR2 and CD10 by prostate cancer was probed in a tissue microarray of over 200 radical prostatectomy cases in which outcomes were known. Immunohistochemistry allowed us to identify different cancer cell phenotypes based on expression levels of these two markers. AGR2 and CD10 expression was further probed in tissue microarrays of bone and soft tissue metastases, and of tumor xenografts, with the expectation that they might reveal phenotypes linked to poor outcomes.

\section{Materials and methods}

This study is approved by our institutional review boards.

\section{Immunohistochemical Analysis of AGR2 and CD10 Gene Expression}

Tissue microarrays. The tissue microarrays of primary tumors and prostate cancer metastasis, and LuCaP prostate cancer xenografts were constructed with cores of 0.6 and $1 \mathrm{~mm}$ in diameter, respectively, from blocks of formalin-fixed, paraffin-embedded tissues. Three tissue microarrays were used: (1) primary prostate tumors (UCLA TMA) constructed from
246 randomly selected hormone-naïve cases treated by surgery with three morphologically representative biopsies of each tumor, plus matching benign tissue and available in situ neoplastic lesions (PIN); biochemical recurrence was the indication used for treatment failure; ${ }^{5,13}$ (2) prostate cancer metastases (UW TMA22) procured from donor autopsies (ie, representative of late-stage disease) with $n=248$ cores from 124 different sites of 23 patients; and (3) the LuCaP series of prostate cancer xenografts, $n=24$, serially passaged in immune compromised mice (UW TMA46).

Tissue microarray immunohistochemistry. For analysis, 6- $\mu$ m-thin sections were cut from each array block. Following deparaffinization and antigen retrieval (by boiling in $0.01 \mathrm{M}$ citrate buffer for $25 \mathrm{~min}$ ), endogenous peroxidase activity was quenched and the sections treated with $5 \%$ goathorse-chicken serum. Slides were incubated overnight with either rabbit polyclonal AGR2 antibody (ab43043; Abcam, Cambridge, MA, USA) at 1:30 or mouse monoclonal CD10 antibody (clone 56C6; Lab Vision, Fremont, CA, USA) at $1: 30$ in $0.1 \%$ bovine serum albumin-phosphate-buffered saline. Specific staining was detected by applying anti-rabbit or anti-mouse horseradish peroxidase-conjugated secondary antibody and avidin-biotin complex followed by diaminobenzidine (Vector ABC, Burlingame, CA, USA). As negative controls, tissue was incubated with concentration-matched non-immune IgG. Frozen sections were also prepared from OCT tissue blocks, and were stained with either monoclonal anti-AGR2 (clone P1G4, IgG1) ${ }^{14}$ at 1:30, or anti-CD10 (clone HI10a, IgG1; BD Bioscience, San Jose, CA, USA) at 1:30.

Tissue microarray scoring for AGR2 and CD10 in primary tumors. The percentage of glandular cell staining was scored from 0 to $100 \%$ and the intensity of staining was rated from 0 (absent immunoreactivity) to 3 (intense). An integrated measure of expression for frequency and intensity of staining was calculated using the following formula: $(3(\% x)+2(\% y)+1(\% z)) / 100$, where $x, y$, and $z$ represented the percentage of cells staining at intensity 3, 2, and 1, respectively. For outcomes analysis, a mean pooled value for each case was calculated. Protein expression was correlated with disease outcome, clinicopathological variables, ${ }^{13}$ and recurrence following radical prostatectomy.

Statistical analysis of correlation between tumor phenotypes and outcome. Briefly, non-parametric two-group and multigroup comparisons were carried out using Mann-Whitney and Kruskal-Wallis tests. Correlations were calculated using Spearman's correlation. Patients were dichotomized at an optimal cut-point, and recurrence-free survival curves were visualized using the Kaplan-Meier method with the difference between outcome distributions 
assessed by the log-rank test. The Cox proportional hazards model was used to test the statistical significance of predictors in both a univariate and a multivariate setting. All statistical analyses were performed with StatView Version 5.0 (SAS Institute, Cary, NC, USA) or with the freely available software package, R (http://www.r-project.org).

AGR2 and CD10 in xenografts and tumor metastases. Tissue microarray immunohistochemistry was similarly performed for the arrays containing the LuCaP xenografts and metastases.

\section{Gene Expression Analysis by Microarrays}

Expression levels from array signal values. The xenografts were maintained and propagated in Balb/ c nu/nu intact male mice, and the castrationresistant variants were developed from parental tumors on regrowth after castration. These were maintained and propagated in castrated B17 Fox Chase SCID male mice (Charles River, Wilmington, MA, USA). ${ }^{15}$ The origin and characteristics of all serially passaged xenografts were described in Corey and Vessella ${ }^{16}$ and Sun et al. ${ }^{17}$ None of these xenografts could be grown in vitro. Xenografts were harvested at $100 \mathrm{mg}$ size, frozen for storage, and each was processed for RNA isolation using STAT60 (Tel-Test, Friendswood, TX, USA).

Metastasis specimens were collected from rapid autopsies of patients who died from metastatic prostate cancer performed under the aegis of the IRB-approved Prostate Cancer Donor Program at the University of Washington Medical Center. ${ }^{18}$ Within $4 \mathrm{~h}$ of death, samples of all gross tumors and bone metastases were obtained under sterile conditions. Each specimen was assigned a unique laboratory research number and rapidly frozen or formalinfixed (bone metastases were decalcified in formic acid) and paraffin embedded. RNA was similarly prepared from frozen specimens using STAT60.

For array analysis, tumor (xenograft and metastasis) RNA was amplified one round and hybridized to Agilent $44 \mathrm{~K}$ whole human genome expression oligonucleotide microarrays (Agilent Technologies, Santa Clara, CA, USA). Probe labeling and hybridization was performed following the Agilent protocol, and fluorescent array images were collected using the Agilent DNA microarray scanner G2565BA. Agilent Feature Extraction software was used to grid, extract, and normalize data as reported in Sharma et al. ${ }^{19}$

\section{AGR2 Protein in Metastasis}

ELISA measurement of tissue digestion media. BD Falcon Flexible (Franklin Lakes, NJ, USA) plates were coated with purified monoclonal antibody P1G4 (1:1000) in phosphate-buffered saline overnight at $4^{\circ} \mathrm{C}$, rinsed $3 \times$ with phosphate-buffered saline-0.05\% Tween, blocked with 1\% heat-denatured bovine serum albumin-phosphate-buffered saline. Cell-free tissue digestion media and spent cancer cell line culture media samples were added for incubation at $4{ }^{\circ} \mathrm{C}$ overnight. Monoclonal antibody P3A5 (IgG2a; 1:1000) ${ }^{14}$ was then added for $1 \mathrm{~h}$ at room temperature. For detection, horse radish peroxidase-conjugated anti-mouse IgG2a was used for $30 \mathrm{~min}$ at room temperature. 2,2'-Azinobis(3ethylbenzothiazoline-6-sulfonic acid)-diammonium salt (KPL/Fisher, Belgium) was the chromogenic reagent for measurement at $\lambda=405 \mathrm{~nm}$. A standard curve was obtained by using recombinant AGR2 (GenWay Biotech, San Diego, CA, USA) as described. ${ }^{14}$

\section{Results}

\section{CD10 and AGR2 Expression Patterns in Primary Prostate Cancer}

In a majority of prostate tumors, AGR2 expression was increased and CD10 expression decreased relative to luminal epithelial cells of benign glands (Figure 1). Thus, cancer cells were $\mathrm{CD}_{10}^{-} \mathrm{AGR} 2^{+}$ and luminal cells were $\mathrm{CD}_{10}{ }^{+} \mathrm{AGR} 2^{-}$. In the example shown, the adjacent tumor and benign glands were clearly distinguished by phenotyping with these two markers. Faint AGR2 staining of the stroma surrounding the cancer glands could indicate that AGR2 was secreted. No such staining feature was seen for CD26 (DPP4), a cell surface antigen on luminal and cancer cells previously used in cell sorting for transcriptome analysis. ${ }^{4}$ This pattern of AGR2 increase and CD10 decrease was also found in the glands of PIN present in this tumor tissue specimen (Figure 1). In cancer cells, AGR2 staining intensity and DNA array expression values for AGR2 probesets ${ }^{4,14}$ indicated moderately abundant levels of the protein and the transcript.

\section{Correlation Between AGR2/CD10 Expression and Clinical Outcome}

We have previously identified a trend of lower AGR2 expression in higher Gleason grades, ${ }^{5}$ and a trend of more $\mathrm{CD}^{+} 0^{+}$tumor cells in higher Gleason grades. ${ }^{8,9}$ In this study, analysis of AGR2 and CD10 expression showed a correlation between the CD10 ${ }^{\text {low } A G R 2 h i g h ~ t u m o r ~ p h e n o t y p e ~ a n d ~ g r e a t e r ~}$ recurrence-free survival in high-stage patients (III/ IV) as shown in Figure 2 (while almost all low-stage (I/II) patients were cured of their disease by surgery). In contrast, patients with CD10 ${ }^{\text {high }} \mathrm{AGR} 2^{\text {low }}$ tumors had the lowest recurrence-free rate. At about 60 months post-surgery, $>80 \%$ of the CD10 ${ }^{\text {low }}$ AGR2high patients showed no recurrence, whereas only $<30 \%$ of the CD10 high AGR2 ${ }^{\text {low }}$ patients did $(P=0.0247)$. Patients with CD10 ${ }^{\text {high }}$ AGR2 $2^{\text {high }}$ and CD10 ${ }^{\text {low }}$ AGR2 ${ }^{\text {low }}$ tumors showed intermediate rates. 


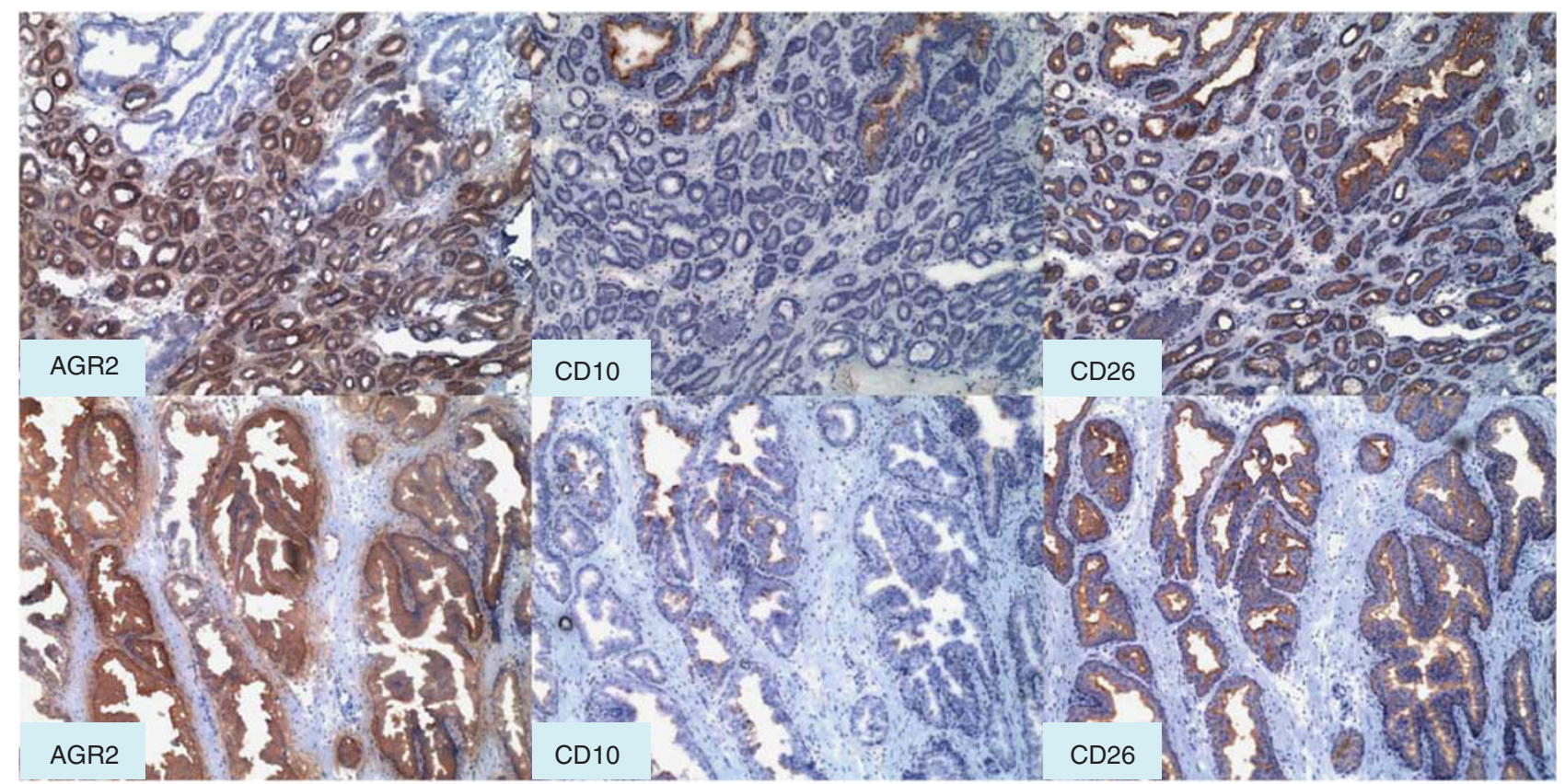

Figure 1 AGR2 (anterior gradient 2) and CD10 expression in prostate cancer. Top: Tumor glands in specimen 99-010D are AGR2+ $\mathrm{CD} 0^{-} \mathrm{CD}_{26}{ }^{+}$, whereas benign glands are AGR2 ${ }^{-} \mathrm{CD} 10^{+} \mathrm{CD} 26^{+}$. Bottom: Prostatic intraepithelial neoplasia (PIN) glands in 99-010D show the same phenotype as cancer glands. Magnification: $\times 100$.

Thus, for high-stage patients whose overall survival was relatively poor, a small group of men with CD10 ${ }^{\text {low } A G R 2 ~}{ }^{\text {high }}$ tumors still experienced a favorable outcome.

High CD10 and low AGR2 expression might be the basis of high disease stage as indicated by the relative percentages of these phenotypes. There were six cases of CD10 ${ }^{\text {low } A G R 2 ~} 2^{\text {high }}(10 \%), 13$ cases of CD10 $10^{\text {high }}$ AGR2 $2^{\text {high }}(21 \%), 8$ cases of CD10 lo${ }^{\text {w AGR2 }} 2^{\text {low }}(13 \%)$, and 36 cases of CD10 ${ }^{\text {high }}$ AGR2 ${ }^{\text {low }}$ $(57 \%)$ in this patient subgrouping. Over half of the high-stage patients contained CD $10^{\text {high }}$ AGR2 ${ }^{\text {low }}$ cancer cells in their tumor, whereas only $10 \%$ contained CD10 ${ }^{\text {low }}$ AGR2 $2^{\text {high }}$ cancer cells in their tumor. Examples of specimens staining for CD10 and AGR2 are shown in Figure 3 for the four phenotypes CD10 ${ }^{+} \mathrm{AGR}_{2}{ }^{+}, \mathrm{CD}_{10}{ }^{-} \mathrm{AGR} 2^{+}, \mathrm{CD} 10^{+} \mathrm{AGR} 2{ }^{-}$, and $\mathrm{CD}^{-}{ }^{-}$AGR2 ${ }^{-}$. Note the first three cases all showed glandular differentiation (ie, Gleason pattern 3), yet the outcome would be different due to their different AGR2/CD10 phenotyping.

Table 1 shows the data set of the tissue microarray cases in pairwise comparison (A grouping vs B grouping). CRR was the current hazard ratio between individual $\mathrm{A}$ and $\mathrm{B}$ groupings where $\mathrm{cRR}<1$ if $\mathrm{A}$ showed higher survival and $>1$ if $\mathrm{B}$ showed higher survival. In row 1 , the $\mathrm{CD} 10^{\text {low }} \mathrm{AGR} 2$ high group showed higher survival by fivefold than the CD10 low AGR2 ${ }^{\text {low }}$ group. This indicated that tumor expression of AGR2 had perhaps a protective effect. In row 5, the CD10 $10^{\text {high }}$ AGR2 $2^{\text {low }}$ group showed lower survival by ninefold than the CD10 ${ }^{\text {low }}$ AGR2 $2^{\text {high }}$ group with the largest observed difference. This indicated that tumor expression of CD10 had a deleterious effect.

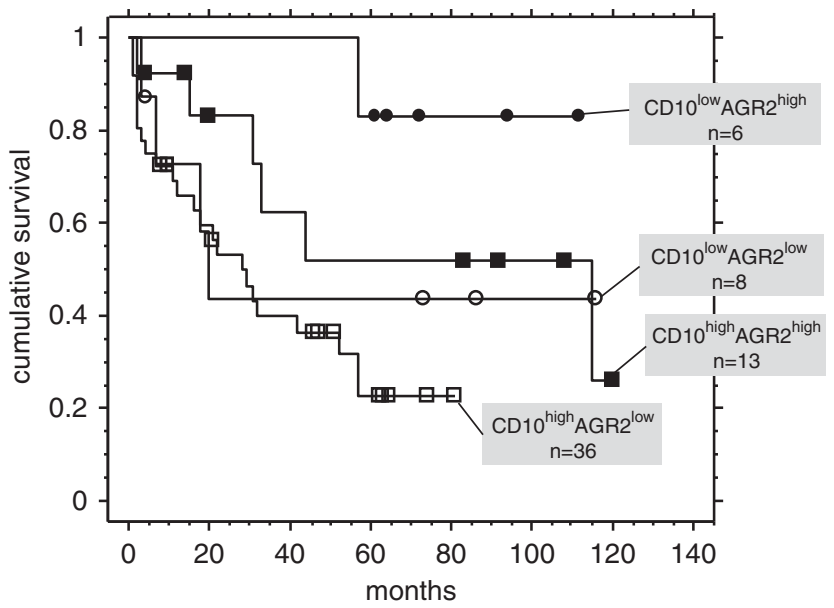

Figure 2 Cancer progression. The Kaplan-Meier plot shows the outcome of high-stage patients grouped by CD10 and AGR2 (anterior gradient 2) expression. At 5 years, 85\% of CD10 low AGR2 ${ }^{\text {high }}$ were recurrence-free compared with just $25 \%$ of CD10 $0^{\text {high }}$ AGR2 ${ }^{\text {low }}$

\section{AGR2 and CD10 Expression in Metastases}

Based on the above findings in primary tumors, one would expect the CD10 ${ }^{\text {high }}$ AGR2 ${ }^{\text {low }}$ phenotype to be predominant in metastases of distal organs. Figure 4 shows immunoreactivity of selected bone/soft tissue metastases. Examples of AGR2/CD10 phenotypes included CD10 ${ }^{\text {low }}$ AGR2 $2^{\text {high }}$ 05-116E2 liver, CD10 ${ }^{\text {lo- }}$ wAGR2high 05-116F2 lung, CD10-AGR2high 06047H2 iliac lymph node, CD10- AGR2- 05-144G1 retroperitoneal lymph node, CD10-AGR2 ${ }^{-}$03192A3 liver, CD10 - AGR2 + 99-064DD1 L4 vertebra, 

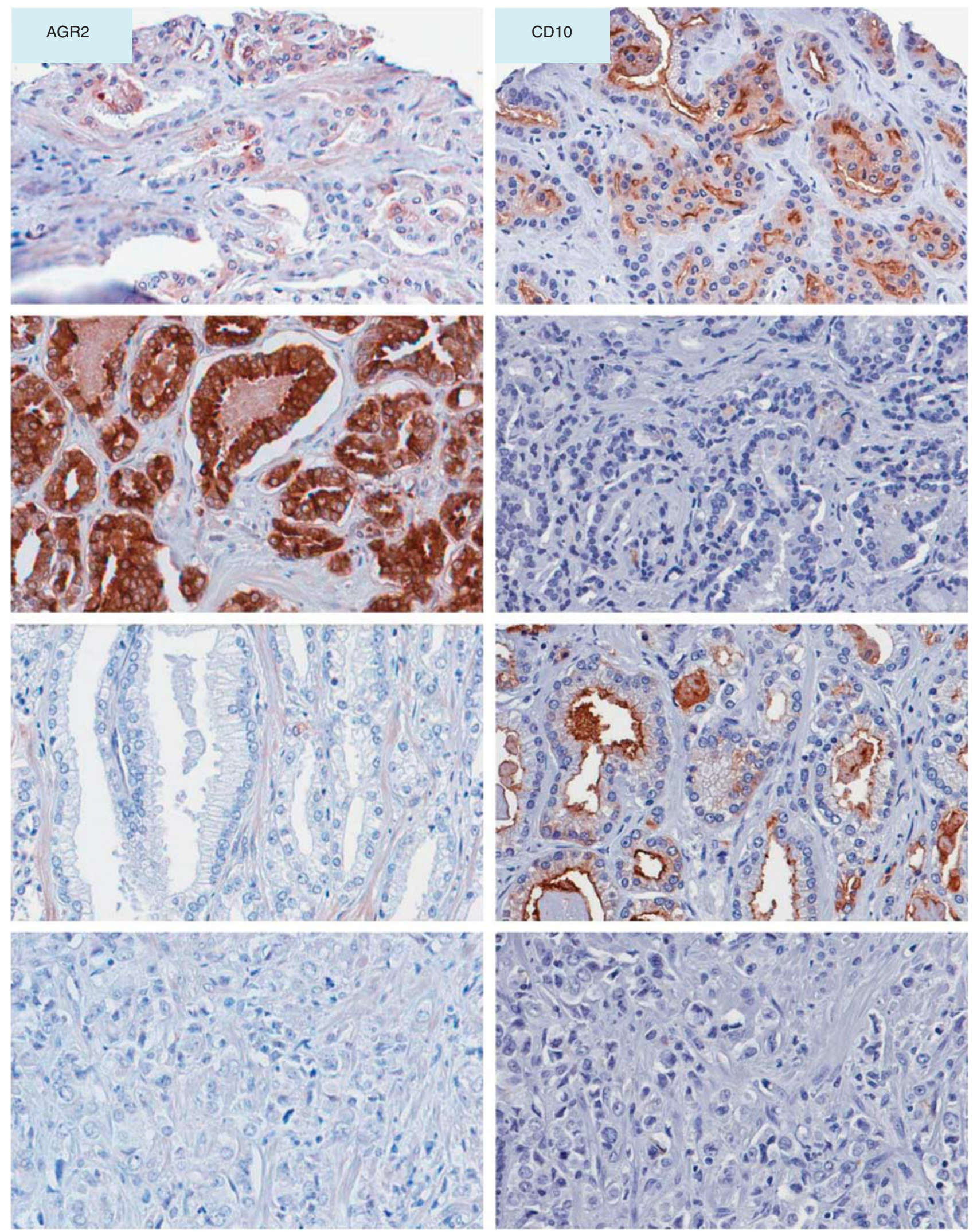

Figure 3 Primary cancer cell phenotypes. Shown are examples of the four different cancer cell phenotypes based on CD10 and AGR2 (anterior gradient 2) immunostaining. Magnification: $\times 100$. 
CD10-AGR2 + 05-214DD4 sacrum, CD10 ${ }^{\text {low } A G R 2-~}$ high 05-011F3 liver, CD10-AGR2 ${ }^{+}$04-050DD3 sacrum, and $\mathrm{CD}_{10}{ }^{-} \mathrm{AGR} 2^{-} 03-082 \mathrm{H} 2$ liver. The tumors showed a range of expression levels (hence the 'high' or 'low' indication) and the staining was cytoplasmic for AGR2. Of these, only 3/10 showed no AGR2 expression, while 7/10 showed no CD10 expression. The AGR2 ${ }^{-}$tumors were all small-cell carcinoma: 05-144G1, 03-192A3, 03-082H2; plus 05144EE1 shown in Figure 5. The AGR2 pattern in metastases was corroborated by DNA microarray analysis (Figure 5). For example, the stronger overall AGR2 staining of $00-140 \mathrm{FF}$ than 07-050EE1 was reflected in the DNA microarray signal values. CD10 expression was also confirmed, and the small-cell carcinoma samples showed low values for CD10 (05144EE2, a sister sampling to 05-144EE1; Figure 5). Thus, the predominant cancer cell phenotype in distal metastasis was not $\mathrm{CD} 10^{\text {high }} \mathrm{AGR} 2^{\text {low }}$ but rather CD10 $0^{\text {low/ }}$-AGR2 ${ }^{\text {high }}$. Note that the metastasis samples were obtained from patients likely treated by androgen ablation and other types of therapy, whereas the primary cancer samples were from patients treated by surgery only.

Table 1 CD10/AGR2 phenotypes and recurrence

\begin{tabular}{|c|c|c|}
\hline$A$ & $B$ & $c R R$ \\
\hline CD10 ${ }^{\text {low }}$ AGR2 $2^{\text {high }}$ & CD10 ${ }^{\text {low }}$ AGR2 $2^{\text {low }}$ & 0.198 \\
\hline CD10 $0^{\text {high }}$ AGR2 $2^{\text {low }}$ & CD10 ${ }^{\text {low }}$ AGR2 $2^{\text {low }}$ & 1.488 \\
\hline CD10 ${ }^{\text {high }}$ AGR2 $2^{\text {high }}$ & CD10 low AGR2 $2^{\text {low }}$ & 0.762 \\
\hline CD10 ${ }^{\text {low }}$ AGR2 $2^{\text {low }}$ & CD10 low AGR2 high & 5.045 \\
\hline CD10 ${ }^{\text {high }}$ AGR2 $2^{\text {low }}$ & CD10 ${ }^{\text {low }}$ AGR $2^{\text {high }}$ & 8.806 \\
\hline CD $10^{\text {high }}$ AGR $2^{\text {high }}$ & CD10 $0^{\text {low }}$ AGR2 $2^{\text {high }}$ & 3.995 \\
\hline
\end{tabular}

$\mathrm{CRR}=$ current hazard ratio; $\mathrm{A}$ and $\mathrm{B}$ are groupings (for more details see the text).

\section{AGR2 Protein in Metastasis Tissue}

Testing of tissue collagenase digestion media by ELISA further supported the AGR2 data. For reference, AGR2 protein in the culture media of cell lines C4-2, C4-2B, CL1 and PC3 was used (Figure 6). C4-2 was negative for AGR2; a small amount was detected in C4-2B; and high amounts in PC3 and CL1. ${ }^{14}$ For multiple metastasis specimens, AGR2 was detected (Figure 6). The specimens were obtained from both donor autopsies and surgical procedures (98-378 bone and 00-061 node).

\section{AGR2 and CD10 Expression in Prostate Cancer Cell Lines and Xenografts}

Figure 7 shows the RNA expression levels of AGR2 and CD10 in cancer cell lines and xenografts. Luminal epithelial cells (L), Gleason pattern 3 (G3) and Gleason pattern 4 (G4) cancer cells of primary tumors (Pascal et al ${ }^{4}$ ) were also shown. C4-2 and CL1 were both derived from LNCaP by androgen manipulation. LuCaP 35 is similar to $\mathrm{LNCaP}$ in gene expression; both were established from positive lymph nodes. ${ }^{20}$ LuCaP 49, characterized by minimal AGR2 and CD10 expression, is representative of small-cell carcinoma. ${ }^{21}$ Among them, these phenotypes were found - $\mathrm{CD}_{10}^{-} \mathrm{AGR}^{+} \mathrm{G} 3$ cancer, CL1, PC3; CD10 ${ }^{\text {high }}$ AGR2 ${ }^{\text {low }}$ LuCaP 35; CD10- ${ }^{-}$GGR2 ${ }^{\text {low }}$ G4 cancer; CD10 ${ }^{+}$AGR2 ${ }^{-}$LNCaP, C4-2; and $\mathrm{CD}_{10}^{-} \mathrm{AGR}^{-}$DU145, LuCaP 49. It appeared that cancer cell lines considered to be more aggressive, PC3 and CL1, showed increased AGR2 and decreased CD10 expression. This was not the case for G3 vs G4 cells of primary tumors where lower levels of AGR2 were found in the potentially more aggressive G4 cells.
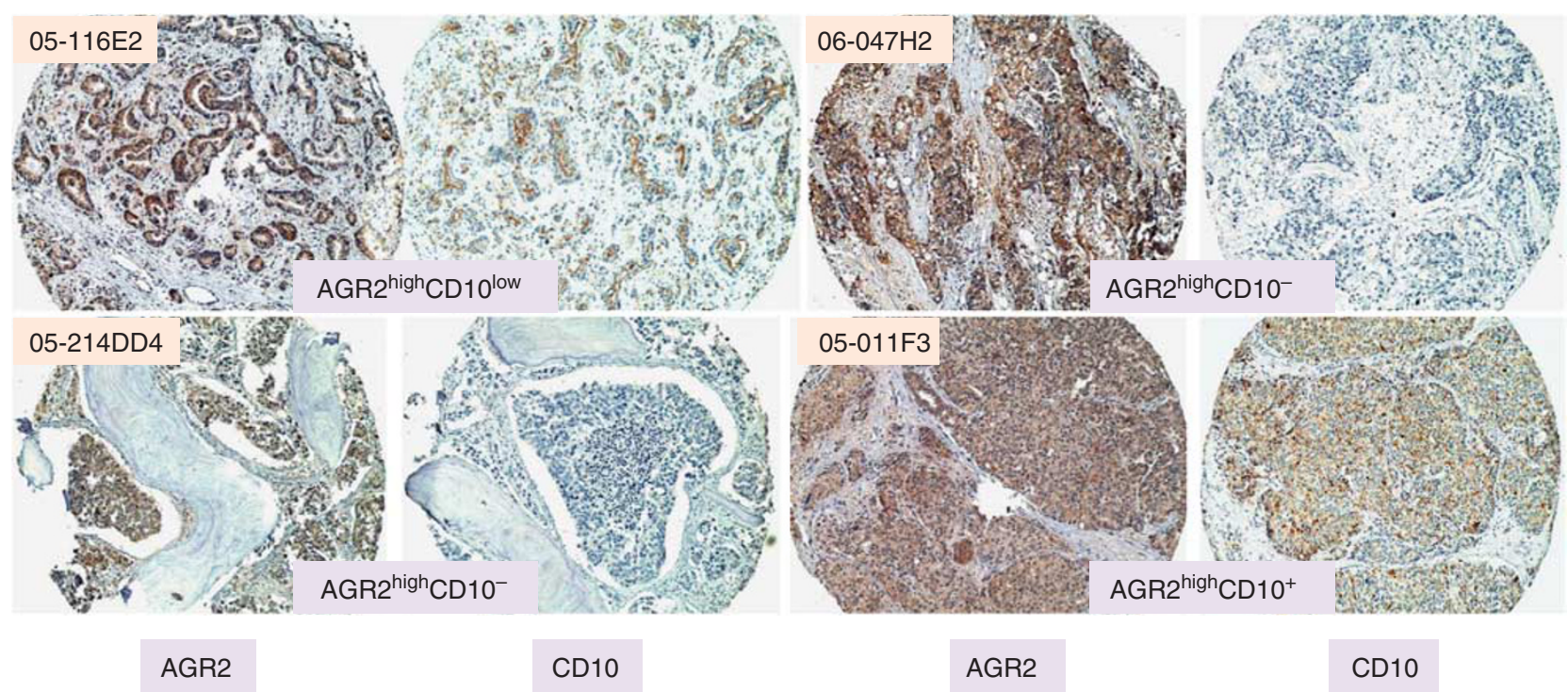

Figure 4 Metastasis phenotypes. Shown are four representative tissue microarray sections of bone and soft tissue metastases, identified by case numbers, stained for AGR2 (anterior gradient 2) and CD10. Their AGR2/CD10 phenotypes are indicated. All four show strong AGR2 reactivity, whereas only two show moderate to weak CD10 reactivity. Magnification: $\times 40$. 

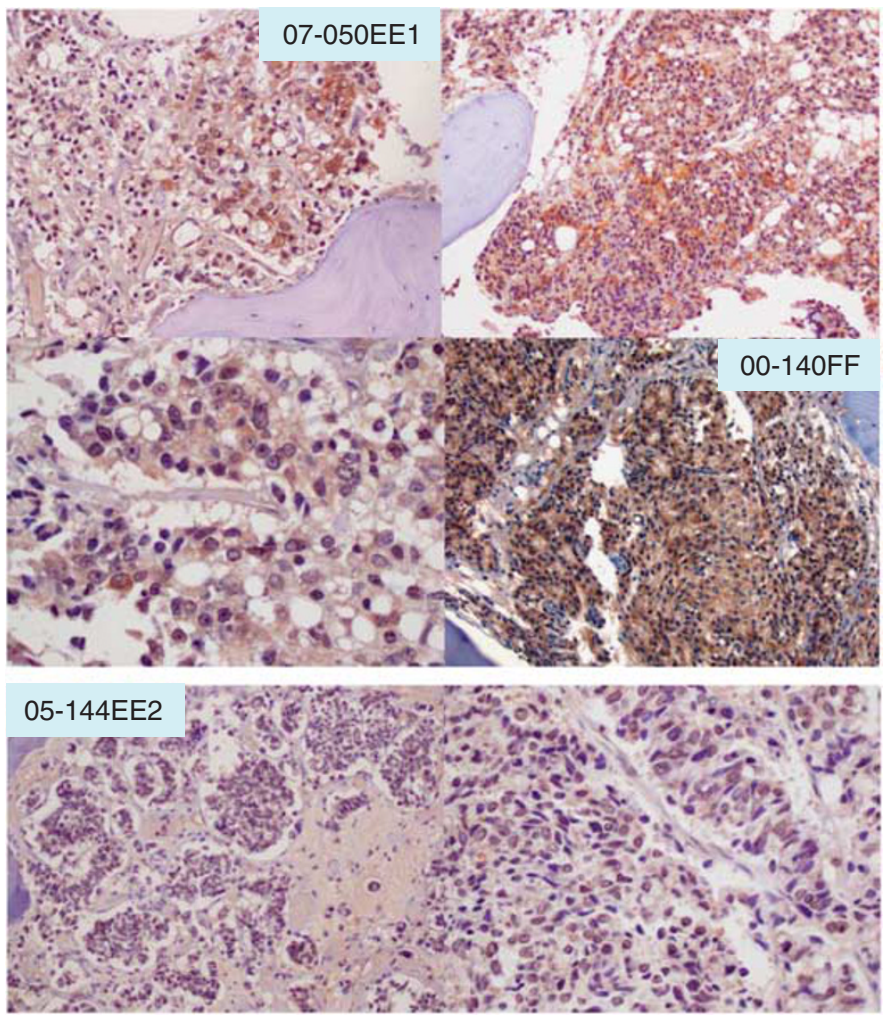

$\downarrow$

$\downarrow$

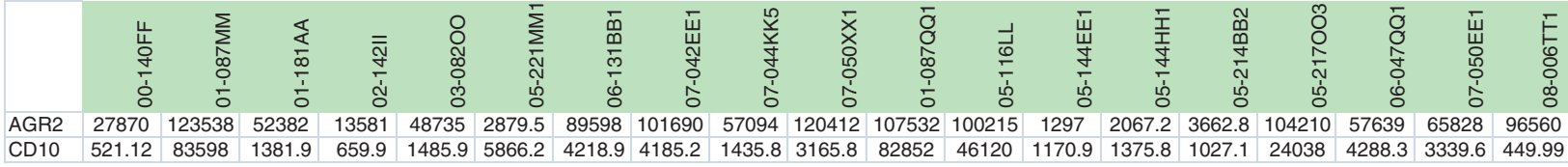

Figure 5 AGR2 (anterior gradient 2) and CD10 RNA expression levels. Shown are AGR2 staining of 07-050EE1 (top section: top two panels magnification $\times 100$ and bottom left magnification $\times 200$ ) and 00-140FF (top section: bottom right magnification $\times 100$ ). AGR2 staining is cytoplasmic. Small cell carcinoma in 05-144EE2 (middle section) is negative for AGR2 (left magnification $\times 100$, right magnification $\times 200$ ). DNA array analysis data of metastases (bottom section) are shown with arrows over the three immunostained specimens shown in the figure. Increased AGR2 expression is denoted by the high CY3 intensity values (red arrows: 27870 and 65828 ) and decreased expression by values (black arrow: 1297). Note the generally lower CY3 intensity values for CD10.

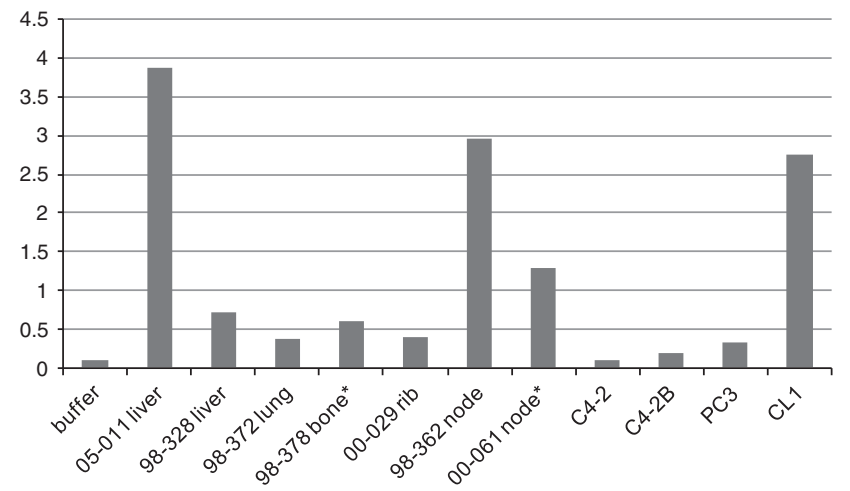

Figure 6 Quantitative measurement of AGR2 (anterior gradient 2) in tissue. The metastasis specimens ( ${ }^{*}$ to indicate from surgery not autopsy) identified on the $\mathrm{x}$ axis were minced and digested by collagenase in culture media overnight, and the cell-free media supernatant was assayed by AGR2 enzyme-linked immunoassay (ELISA). $\mathrm{OD}_{405}$ readings are indicated on the y axis. The first bar indicates the level obtained with buffer/media only. Levels in culture supernatant of C4-2, C4-2B, PC3, and CL1 are included for comparison. OD, optical density.

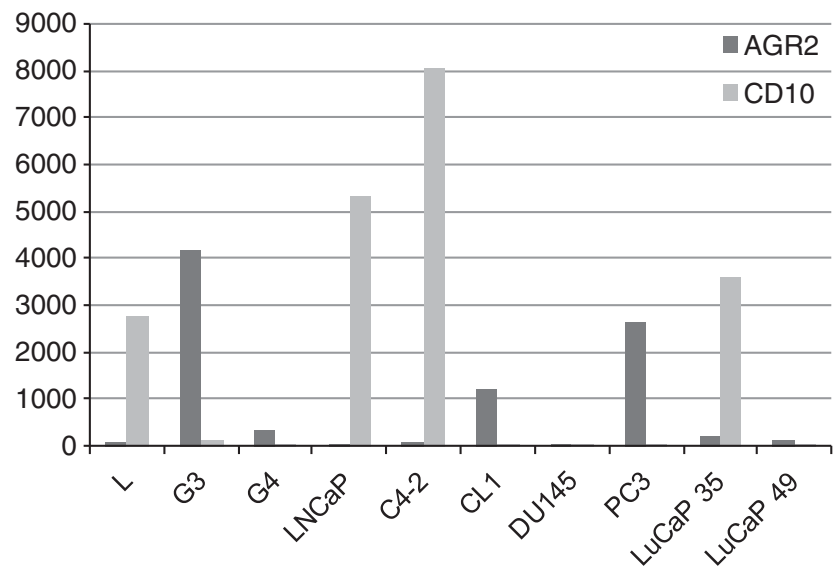

Figure 7 Cancer cell AGR2 (anterior gradient 2)/CD10 RNA expression levels. Levels were determined through DNA microarray analysis with signal intensity values on the y axis. Indicated on the $\mathrm{x}$ axis are L (luminal), G3 and G4 primary tumor cell types, LNCaP, C4-2, CL1, DU145, PC3 cell lines, and LuCaP35, LuCaP 49 xenografts. Except for DU145 and LuCaP 49, the expression pattern is either CD10 or AGR2. 
Figure 8 shows immunostains of LuCaP xenografts (Table 2) harvested from subcutaneous tumors passaged in mice. The AGR2/CD10 phenotypes were: CD10 ${ }^{\text {low }}$ AGR2 $2^{\text {high }} \mathrm{LuCaP} 23.12$ (established from a liver metastasis), LuCaP 105 (rib); CD10 highAGR2 ${ }^{\text {low }}$ LuCaP 141 (transurethral resection of the prostate), LuCaP 86.2 (bladder); CD10 ${ }^{\text {low }}$ AGR2 $2^{\text {low }}$ LuCaP 81 (lymph node); and CD10- AGR2 ${ }^{-}$LuCaP 145.1 (liver). LuCaP 145.1 was representative of small-cell carcinoma, and like LuCaP 49 (and LuCaP 93, LuCaP 145.2), was negative for both markers. LuCaP 141, established from a surgical specimen of primary cancer, and LuCaP 86.2, from a resected bladder metastasis, expressed CD10. Protein expression was corroborated by DNA microarray analysis of these xenografts (Figure 9).

LuCaP 35CR, LuCaP 96CR, and $\mathrm{LuCaP}$ 23.1CR $(\mathrm{CR}=$ castration resistant $)$ provided a means to examine the effect of androgen ablation on the expression of AGR2 and CD10. Based on immunostaining, the phenotypes were $\mathrm{CD}_{10}^{-} \mathrm{AGR}^{-}$for LuCaP 23.1, CD10 ${ }^{\text {high }} A G R 2$ low for $\mathrm{LuCaP} 35$, and CD10 ${ }^{\text {low }}$ AGR2 ${ }^{\text {high }}$ for LuCaP 96. It is unclear why the DNA microarray results for LuCaP 23.1 and LuCaP 96 were discordant with immunostaining (Figure 9). Androgen removal appeared to reduce overall staining of CD10 in LuCaP 96CR (Figure 10). DNA array analysis also showed a decrease in LuCaP 96CR (Figure 9). For AGR2, some weak focal staining in
LuCaP 23.1CR, and strong staining between tumor cells in LuCaP 96CR was detected (Figure 10). These results were akin to that in the derivation of $\mathrm{CD} 10^{+}$ AGR2 - C4-2 from CD10 ${ }^{+}$AGR2 ${ }^{-}$LNCaP in castrated animals. As the LuCaP tumors cannot be cultured in vitro, a similar pathway (ie, long-term growth in androgen-free media) to obtain CD10-AGR2 ${ }^{+}$CL1 from LNCaP could not be duplicated.

\section{Discussion}

AGR2 and CD10 are both biomarkers for prostate cancer. AGR2 expression is lower in cancer cells of higher grades, whereas CD10 ${ }^{+}$cancer cells are more frequent in higher grade cancers. A small subset of tumors with similar Gleason pattern show differential AGR2/CD10 expression; therefore, AGR2/CD10 phenotyping would perhaps be more useful than Gleason scoring in predicting outcome. AGR2 appears to be protective while CD10 imparts a more aggressive potential in prostate cancer. Thus, even for high-stage patients where overall survival is poor, tumors showing high AGR2 and low CD10 expression would still predict a better outcome. While both AGR2 and CD10 are independently prognostic, in combination, three phenotypes define recurrence probability from low to high: CD10 ${ }^{\text {low } A G R 22^{\text {high }}<C D 10^{\text {high }} \text { AGR2 }}{ }^{\text {high }}=$ CD10 ${ }^{\text {low }}$ AGR2 $2^{\text {low }}<$ CD10 $0^{\text {high }}$ AGR2 ${ }^{\text {low }}$. The precise molecular functioning of the two proteins in cancer

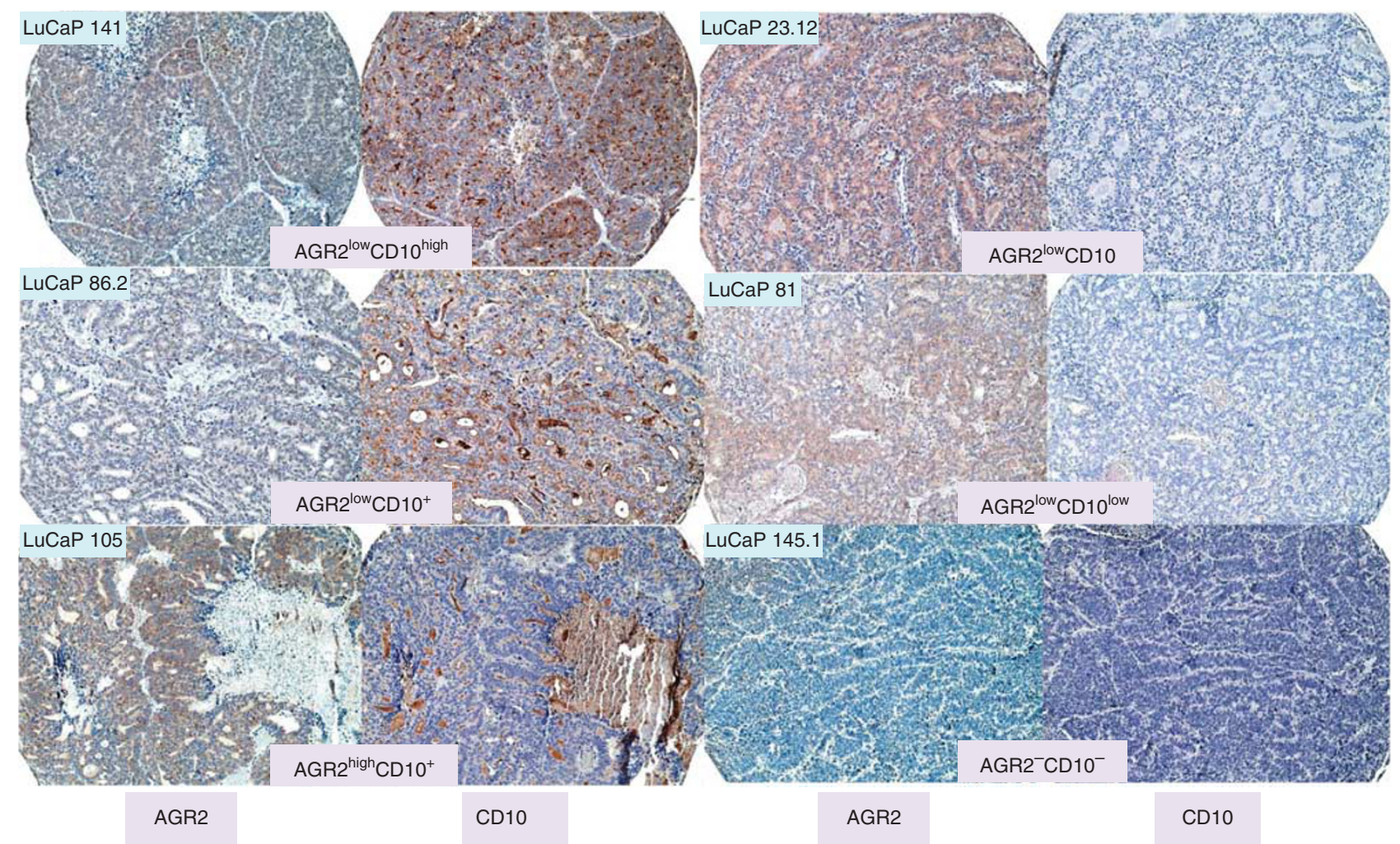

Figure 8 LuCaP phenotypes. Staining results for six LuCaP xenografts and their AGR2 (anterior gradient 2)/CD10 phenotypes are shown, magnification $\times 40$. Where staining is absent a ' - 'sign is used, or present a ' +' sign is used. 'High' or 'low' are used to indicate strong or weak staining. 
Table 2 LuCaP xenograft AGR2/CD10 phenotypes

\begin{tabular}{|c|c|c|c|c|c|}
\hline LuCaP & Source & $\begin{array}{l}\text { AGR2 by } \\
\text { array }\end{array}$ & $\begin{array}{c}\text { AGR2 } \\
\text { by IHC }\end{array}$ & $\begin{array}{l}\text { CD10 by } \\
\text { array }\end{array}$ & $\begin{array}{l}\text { CD10 } \\
\text { by IHC }\end{array}$ \\
\hline 23.1 & Lymph node & High & - & Low & - \\
\hline 23.1CR & Experimental & High & $-1+$ & Low & - \\
\hline 23.12 & Liver & High & +++ & Low & - \\
\hline 35 & Lymph node & Medium & ++ & High & ++ \\
\hline 35CR & Experimental & Medium & ++ & High & ++ \\
\hline 49 (scc) & Omental fat ${ }^{\mathrm{a}}$ & Low & - & Low & - \\
\hline 58 & Lymph node & Medium & - & Medium & - \\
\hline 70 & Liver & Medium & $-1+$ & High & ++ \\
\hline 73 & Prostate $^{\mathrm{a}}$ & Medium & - & Medium & $+1-$ \\
\hline 77 & Femur & Medium & + & Medium & + \\
\hline 78 & Lymph node & High & + & Medium & ++ \\
\hline 81 & Lymph node & High & ++ & Medium & - \\
\hline 86.2 & Bladder ${ }^{\mathrm{a}}$ & Medium & + & High & +++ \\
\hline 92 & Lymph node & Low & $+1-$ & Medium & - \\
\hline 93 (scc) & TURP ${ }^{\mathrm{a}}$ & Low & $+1-$ & Low & - \\
\hline 96 & TURP $^{\mathrm{a}}$ & Low & +++ & Medium & $+1-$ \\
\hline 96CR & Experimental & Low & +++ & Low & $+1-$ \\
\hline 105 & Rib & High & ++ & Medium & ++ \\
\hline 115 & Lymph node & Medium & $+1-$ & High & ++ \\
\hline 136 & Ascites $^{\mathrm{a}}$ & High & + & Low & $-1+$ \\
\hline 141 & TURP ${ }^{\mathrm{a}}$ & Low & ++ & High & +++ \\
\hline 145.1 (scc) & Liver & Low & - & Low & - \\
\hline 145.2 (scc) & Lymph node & Low & $-1+$ & Medium & - \\
\hline 147 & Liver & High & ++ & Medium & $-1+$ \\
\hline
\end{tabular}

$\mathrm{CR}=$ castration resistant $\mathrm{IHC}=$ immunohistochemistry $\mathbf{s c C}=$ smallcell carcinoma; TURP $=$ transurethral resection of the prostate.

Degree of immunostaining is indicated by the ' + ' signs; ' $-/+$ ' and ' $+I_{-}$' are used to indicate very weak or spotty staining.

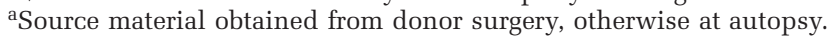

cells is unknown. Note the luminal cell CD10 ${ }^{+}$ AGR2- phenotype corresponds to the aggressive CD10 ${ }^{\text {high }}$ AGR2 $2^{\text {low }}$ cancer type. The action of these gene products are likely dependent on cell context. Similarly, although G3 cancer and CL1 shared a common phenotype in AGR2 and CD10, their overall gene expression is very different. ${ }^{20}$

The expression pattern of AGR2 and CD10 in distal metastases of the bone and soft tissues appears at odds with that in primary tumors where potential of cancer spread is correlated with Gleason grade. The majority of these metastases are typed CD10 ${ }^{\text {low } A G R 2 ~}{ }^{\text {high }}$, whereas this phenotype predominates in Gleason 3. Instead, the CD10 ${ }^{\text {high }}$ AGR2 ${ }^{\text {low }}$ phenotype in primary tumors is correlated with poor outcome. Most regional lymph node metastases contain $\mathrm{CD} 10^{+} \mathrm{AGR} 2^{-1+}$ tumor cells. For example, $\mathrm{CD}_{10}{ }^{+} \mathrm{AGR} 2{ }^{-} \mathrm{LNCaP}$ and $\mathrm{CD} 10^{+} \mathrm{AGR} 2{ }^{+} \mathrm{LuCaP} 35$ are both derived from node metastasis. Outside their metastasis potential, the transcriptomes of LNCaP and LuCaP 35 are similar to that of CD10 ${ }^{+}$AGR2 ${ }^{-}$luminal cells and CD10 ${ }^{-}$AGR2 ${ }^{+}$G3 cancer cells. ${ }^{20}$ Additionally, LuCaP 86.2, established from a surgically resected bladder metastasis (representative of local spread), is CD10 ${ }^{\text {high }}$. This suggests that $\mathrm{CD} 10^{+}$tumor cells are more likely to escape the prostate than $\mathrm{CD}_{10}^{-}$ones. For distal spread, the functional role of AGR2 becomes more
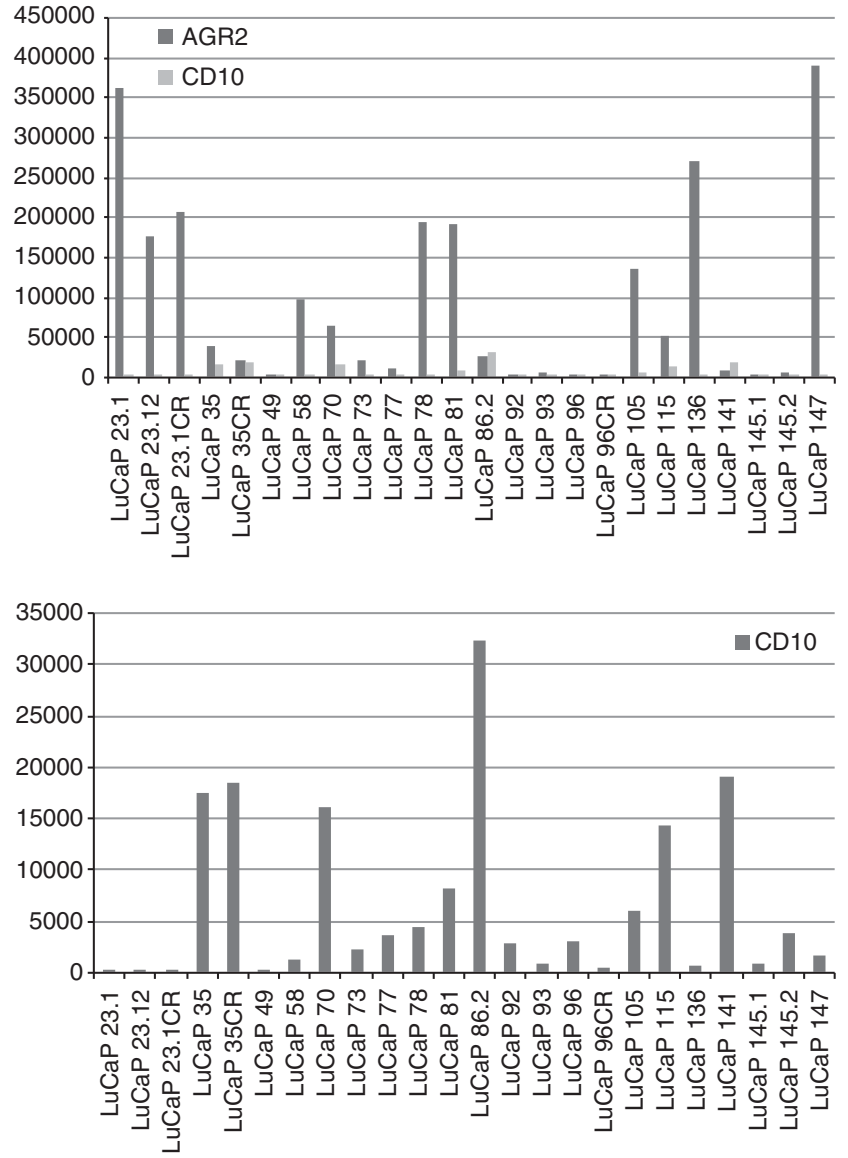

Figure 9 Expression levels of AGR2 (anterior gradient 2) and CD10 in xenografts. As inferred from DNA microarray analysis, these levels are presented in histogram format (top). CY3 intensity values are indicated on the y axis. Because of the lower values for CD10, a separate histogram for CD10 is included (bottom). Note the $\sim 6$-fold decrease in CD10 from LuCaP 96 to LuCaP 96CR.

important, whereas that of CD10 becomes less important. This hypothesis could explain the expression pattern seen in bone and other organ metastases, which is in line with the experimental data showing AGR2 promoted tumor cell growth and dissemination. ${ }^{22-26}$ What, then, could cause the phenotypic change to $\mathrm{CD} 10^{-} \mathrm{AGR} 2^{+}$from escaped CD10 ${ }^{+} \mathrm{AGR}^{-}$tumor cells? One possible mechanism involves physiological stress such as serum depletion or oxygen starvation on cancer cell AGR2 expression. ${ }^{27}$ Hormone ablation is a physiological stress for prostate cancer cells. The LNCaP cell line was grown in androgen-free media to obtain the androgen-independent variant CL1. ${ }^{28}$ CL1 expresses AGR2 at a high level. LNCaP was also grown in castrated mice with human bone stromal cells to obtain C4-2, and C4-2 was further selected for growth in bone to obtain C4-2B. ${ }^{29}$ While C4-2 remains $\mathrm{CD}_{10}{ }^{+} \mathrm{AGR} 2^{-}, \mathrm{C} 4-2 \mathrm{~B}$ produces a small amount of AGR2. PC3, established from a bone metastasis ${ }^{30}$ is AGR2 ${ }^{+}$. With the gain of AGR2 expression, the CL1 cells have also lost CD10 expression. ${ }^{31}$ In the castration-resistant LuCaP variants, some weak 


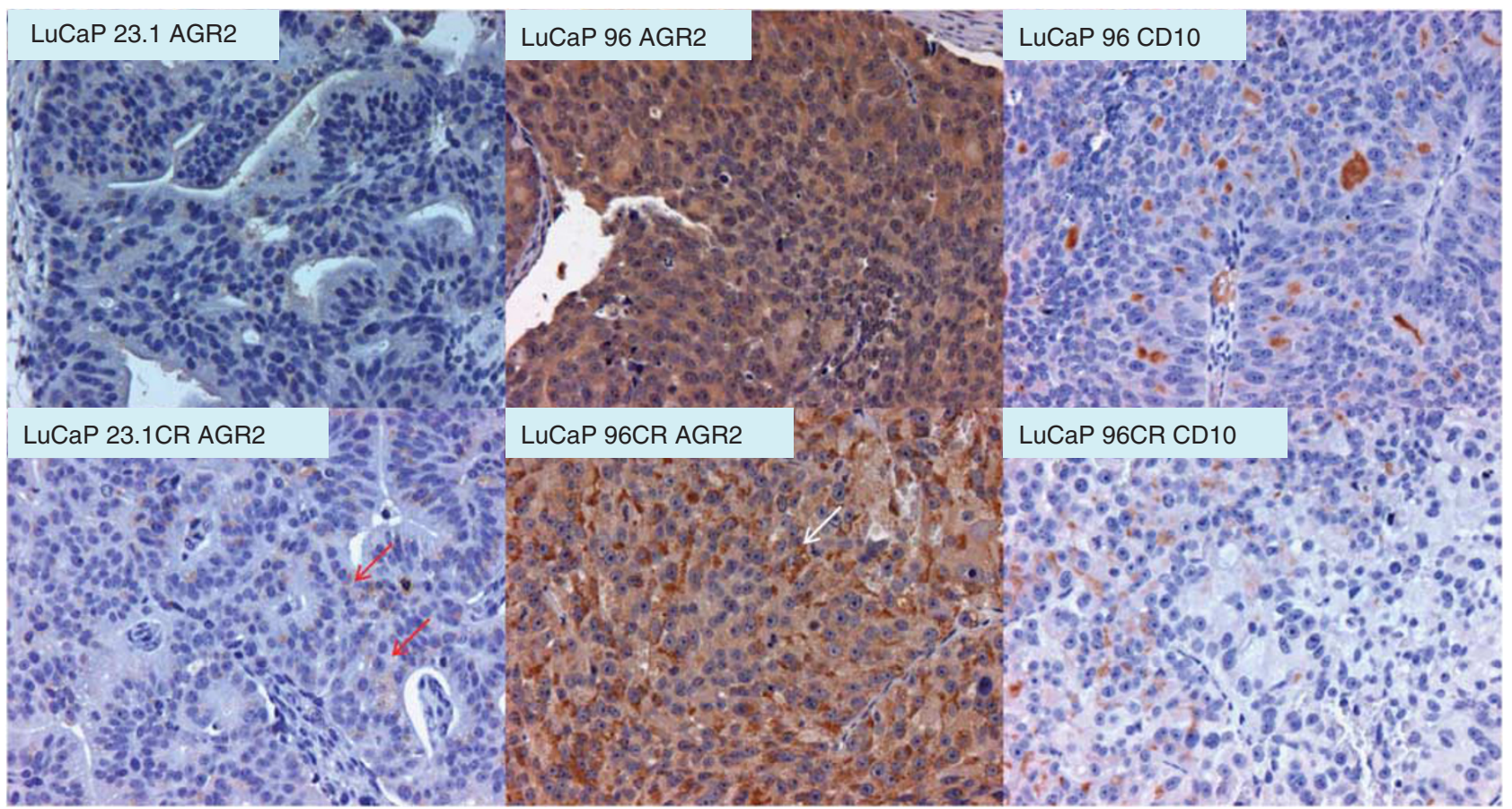

Figure 10 Castration-resistant LuCaP xenografts. Staining between LuCaP 23.1 and LuCaP 23.1CR for AGR2 (anterior gradient 2), between LuCaP 96 and LuCaP 96CR for AGR2 and CD10 are shown, magnification $\times 200$. Red arrows in the LuCaP23.1CR AGR2 panel show examples of weak cytoplasmic staining of tumor cells. The white arrow in the LuCaP 96CR AGR2 panel shows intercellular AGR2 reactivity. Note the overall decreased CD10 staining in the LuCaP 96CR CD10 panel than in the LuCaP 96 CD10 panel.

staining of AGR2 is present in LuCaP 23.1CR vs complete absent staining in LuCaP 23.1; a decrease in overall CD10 staining is seen in LuCaP 96CR vs LuCaP 96. This complex expression pattern of CD10 and AGR2 in prostate cancer could explain discrepant conclusions reported in the literature regarding their prognostic value: CD10 expression was correlated with better outcome; ${ }^{7}$ AGR2 expression was correlated with poorer outcome. ${ }^{32}$ A similar situation may exist for AGR2 in breast cancer where expression is correlated with poor survival by one study $^{33}$ vs that with better survival by another. ${ }^{34}$ In the latter case, AGR2 expression is associated breast cancer differentiation and lower tumor grade as in prostate cancer.

Our working hypothesis is that CD10 and AGR2 have opposing functions in prostate cancer cells. Luminal CD10 expression is lost and AGR2 expression is gained early in cancer development. Certain cancer cells regain CD10 expression (or retain luminal CD10 expression) with or without decrease in AGR2 expression in progression from low to high Gleason grade. CD10 allows the cancer cells to escape the prostate to regional lymph nodes and proximal organs like the bladder. In order for distal spread to organs like bone, the cancer cells require functional AGR2. This hypothesis is supported by the result showing that a surgically removed bone lesion, specimen 98-378, was $\mathrm{AGR} 2^{+}$, and by the fact that CL1 cells are highly metastatic in mice, whereas LNCaP cells are not. ${ }^{28}$ The LNCaP to CL1 pathway suggests that AGR2 expression could be triggered by a physiological stress such as androgen ablation used in the treatment of postoperative patients with rising PSA.

In summary, the prostate cancer biomarkers, AGR2 and CD10, can be used in combination to stratify prostate cancer patients for clinical outcome. Patients with CD10 ${ }^{\text {high }}$ AGR2 ${ }^{\text {low }}$ tumors would appear to fare worse than those with CD10 ${ }^{\text {low }}$ AGR2 $2^{\text {high }}$ tumors. However, cancer cells in distal metastases of advanced disease are CD10 ${ }^{\text {low }}$ AGR2 ${ }^{\text {high }}$.

\section{Acknowledgements}

The research was supported by the NCI Early Detection Research Network (EDRN) Grants CA111244 (AYL), CA86366 (DC, LG) and the Pacific Northwest SPORE P50 CA097186 (LDT, CM, EC, RLV, PSN). We thank the patients, families, and clinicians Celestia Higano, Bruce Montgomery, and Martine Roudier in the Rapid Autopsy Program at University of Washington for making available the study materi$\mathrm{al}$, and Adeline Chen for performing immunostaining.

\section{Disclosure/conflict of interest}

The authors declare no conflict of interest. 


\section{References}

1 Thompson IM, Pauler DK, Goodman PJ, et al. Prevalence of prostate cancer among men with a prostatespecific antigen level <or $=4.0 \mathrm{ng}$ per milliliter. N Engl J Med 2004;350:2239-2246.

$2 \mathrm{Yu}$ JB, Makarov DV, Sharma R, et al. Validation of the Partin nomogram for prostate cancer in a national sample. J Urol 2010;183:105-111.

3 Zhang JS, Gong A, Cheville JC, et al. AGR2, an androgen-inducible secretory protein overexpressed in prostate cancer. Genes Chromosomes Cancer 2005;43:249-259.

4 Pascal LE, Vêncio RZN, Page LS, et al. Gene expression relationship between prostate cancer cells of Gleason 3, 4 and normal epithelial cells as revealed by cell type-specific transcriptomes. BMC Cancer 2009;9:452.

5 Maresh EL, Mah V, Alavi M, et al. Differential expression of anterior gradient gene AGR2 in prostate cancer. BMC Cancer 2010;10:680.

$6 \mathrm{Bu} \mathrm{H}$, Bormann S, Schäfer G, et al. The anterior gradient 2 (AGR2) gene is overexpressed in prostate cancer and may be useful as a urine sediment marker for prostate cancer detection. Prostate 2011;71:575-587.

7 Osman I, Yee H, Taneja SS, et al. Neutral endopeptidase protein expression and prognosis in localized prostate cancer. Clin Cancer Res 2004;10:4096-4100.

8 Liu AY, Roudier MP, True LD. Heterogeneity in primary and metastatic prostate cancer as defined by cell surface CD profile. Am J Pathol 2004;165:1543-1556.

9 Dall'Era MA, True LD, Siegel AF, et al. Differential expression of CD10 in prostate cancer and its clinical implication. BMC Urol 2007;7:3.

10 Fleischmann A, Rocha C, Saxer-Sekulic N, et al. High CD10 expression in lymph node metastases from surgically treated prostate cancer independently predicts early death. Virchows Arch 2011;458:741-748.

11 Fleischmann A, Schlomm T, Huland H, et al. Distinct subcellular expression patterns of neutral endopeptidase (CD10) in prostate cancer predict diverging clinical courses in surgically treated patients. Clin Cancer Res 2008;14:7838-7842.

12 Dall'Era MA, Oudes A, Martin DB, et al. Identification of HSP27 and HSP70 as CD10 binding proteins in prostate cancer cells. Prostate 2007;67:714-721.

13 Seligson DB, Hongo F, Huerta-Yepez S, et al. Expression of X-linked inhibitor of apoptosis protein is a strong predictor of human prostate cancer recurrence. Clin Cancer Res 2007;13:6056-6063.

14 Wayner EA, Quek S, Ahmad R, et al. Development of an ELISA to detect the secreted prostate cancer biomarker AGR2 in voided urine. Prostate 2012;72: 1023-1034.

15 Coleman IM, Kiefer JA, Brown LG, et al. Inhibition of androgen-independent prostate cancer by estrogenic compounds is associated with increased expression of immune-related genes. Neoplasia 2006;8:862-878.

16 Corey E, Vessella RL. Xenograft models of human prostate cancer, In: Chung LW, Isaacs WB, Simons JWeds) Prostate Cancer: Biology, Genetics and the New Therapeutics. Humana Press: Totowa, NJ; 2007, pp 3-31.

17 Sun S, Sprenger CCT, Vessella RL, et al. Castration resistance in human prostate cancer is conferred by a frequently occurring androgen receptor splice variant. J Clin Invest 2010;120:2715-2730.

18 Roudier MP, True LD, Higano CS, et al. Phenotypic heterogeneity of end-stage prostate carcinoma metastatic to bone. Hum Pathol 2003;34:646-653.

19 Sharma A, Yeow WS, Ertel A, et al. The retinoblastoma tumor suppressor controls androgen signaling and human prostate cancer progression. J Clin Invest 2010; 120:4478-4492.

20 Pascal LE, Vêncio RZN, Vessella RL, et al. Lineage relationship of prostate cancer cell types based on gene expression. BMC Med Genomics 2011;4:46.

21 True LD, Buhler K, Quinn J, et al. A neuroendocrine/ small cell prostate carcinoma xenograft-LuCaP 49. Am J Pathol 2002;161:705-715.

22 Wang Z, Hao Y, Lowe AW. The adenocarcinomaassociated antigen, AGR2, promotes tumor growth, cell migration, and cellular transformation. Cancer Res 2008;68:492-497.

23 Ramachandran V, Arumugam T, Wang H, et al. Anterior gradient 2 is expressed and secreted during the development of pancreatic cancer and promotes cancer cell survival. Cancer Res 2008;68:7811-7818.

24 Vanderlaag KE, Hudak S, Bald L, et al. Anterior gradient-2 plays a critical role in breast cancer cell growth and survival by modulating cyclin D1, estrogen receptor-alpha and surviving. Breast Cancer Res 2010; 12:R32.

25 Park K, Chung YJ, So $\mathrm{H}$, et al. AGR2, a mucinous ovarian cancer marker, promotes cell proliferation and migration. Exp Mol Med 2011;43:91-100.

26 Dumartin L, Whiteman HJ, Weeks ME, et al. AGR2 is a novel surface antigen that promotes the dissemination of pancreatic cancer cells through regulation of cathepsins B and D. Cancer Res 2011;71:7091-7102.

27 Zweitzig DR, Smirnov DA, Connelly MC, et al. Physiological stress induces the metastasis marker AGR2 in breast cancer cells. Mol Cell Biochem 2007;306:255-260.

28 Patel BJ, Pantuck AJ, Zisman A, et al. CL1-GFP: an androgen independent metastatic tumor model for prostate cancer. J Urol 2000;164:1420-1425.

29 Chen ME, Lin SH, Chung LW, et al. Isolation and characterization of PAGE-1 and GAGE-7. New genes expressed in the LNCaP prostate cancer progression model that share homology with melanoma-associated antigens. J Biol Chem 1998;273:17618-17625.

30 Kaighn ME, Lechner JF, Babcock MS, et al. The Pasadena cell lines. Prog Clin Biol Res 1980;37: 85-109.

31 Freedland SJ, Seligson DB, Liu AY, et al. Loss of CD10 (neutral endopeptidase) is a frequent and early event in human prostate cancer. Prostate 2003;55:71-80.

32 Zhang Y, Forootan SS, Liu D, et al. Increased expression of anterior gradient-2 is significantly associated with poor survival of prostate cancer patients. Prostate Cancer Prostatic Dis 2007;10: 293-300.

33 Barraclough DL, Platt-Higgins A, de Silva Rudland S, et al. The metastasis-associated anterior gradient 2 protein is correlated with poor survival of breast cancer patients. Am J Pathol 2009;175:1848-1857.

34 Fritzsche FR, Dahl E, Pahl S, et al. Prognostic relevance of AGR2 expression in breast cancer. Clin Cancer Res 2006;12:1728-1734. 